\title{
Tobacco Genes Induced by the Bacterial Effector Protein AvrPto
}

\author{
Venkatappa K. Thara, ${ }^{1}$ Alexander R. Seilaniantz, ${ }^{1}$ Youping Deng, ${ }^{2}$ Yinghua Dong, ${ }^{2}$ Yinong Yang, ${ }^{3}$ \\ Xiaoyan Tang, ${ }^{1}$ and Jian-Min Zhou ${ }^{1}$
}

${ }^{1}$ Department of Plant Pathology, Kansas State University, Manhattan, KS, U.S.A.; ${ }^{2}$ Division of Biology, Kansas State University, Manhattan, KS, U.S.A.; ${ }^{3}$ Department of Plant Pathology, University of Arkansas, Fayetteville, AR, U.S.A.

Submitted 5 May 2004. Accepted 28 June 2004.

\begin{abstract}
The type III effector protein AvrPto acts as a virulence factor in susceptible plants lacking a cognate resistance gene but triggers hypersensitive response and disease resistance in tomato plants carrying the Pto gene or in tobacco plants carrying an unknown resistance gene. To assist the characterization of cellular responses caused by AvrPto in the plant, a pathogen-free system was adopted to isolate genes up-regulated $12 \mathrm{~h}$ after induced expression of AvrPto. By using subtraction cloning and transgenic tobacco plants expressing avrPto as a transgene, we isolated 125 nonredundant cDNA clones that represent avrPto-response genes $(A R G)$. In addition to genes that are known to be induced by Pto-avrPto recognition, a number of new genes were also isolated. Most of $A R G$ showed a specific induction in tobacco plants challenged with incompatible or nonhost pathogens. The use of an avrPto mutant that selectively eliminated the avrPto recognition in tobacco demonstrated that the $A R G$ were induced in a highly specific manner by the avirulence, instead of the virulence activity of avrPto.
\end{abstract}

Additional keywords: subtracted cDNA library, Pseudomonas syringae.

Phytopathogenic bacterial type III effectors are important determinants in plant disease susceptibility and resistance (Galan and Collmer 1999). These proteins are secreted into host cells to promote parasitism. However, an effector can betray the pathogen when the host plant has acquired a corresponding resistance protein that either directly or indirectly detects the presence of the effector. This phenomenon is also referred to as gene-for-gene resistance (Flor 1956). Thus, understanding the cellular activities of type III effectors has been a major focus of recent studies of plant-bacterial interactions (Axtell and Staskawicz 2003; Chang et al. 2004; Hauck et al. 2003; Mackey et al. 2002; Nimchuk et al. 2000; Shan et al. 2000b; Zhao et al. 2003). The Pseudomonas syringae pv. tomato AvrPto protein has served as a model for the secretion and function of bacterial type III effector proteins. In tomato plants lacking a cognate resistance gene, AvrPto functions as a

Corresponding author: J.-M. Zhou; E-mail: jzhou@ksu.edu; Telephone: 785-532-2415; Fax: 785-532-5692.

Current address for V. K. Thara: Department of Biochemistry and Cell Biology, Rice University, Houston, TX, U.S.A.

*The $\boldsymbol{e}$-Xtra logo stands for "electronic extra" and indicates the HTML abstract available on-line contains a supplemental table not included in the print edition. virulence factor (Chang et al. 2000; Shan et al. 2000a). In tomato plants carrying the corresponding resistance gene Pto, AvrPto triggers hypersensitive response (HR) resistance (Scofield et al. 1996; Tang et al. 1996).

Significant effort has been made toward the understanding of the function of AvrPto in bacterial virulence and plant disease resistance. A recent study suggests that AvrPto suppresses cell wall-based defense in Arabidopsis (Hauck et al. 2003). Disease resistance specified by Pto-avrPto interaction has been a model for the understanding of mechanisms involved in gene-for-gene interaction. Unlike many other resistance geneavirulence gene pairs, direct Pto-AvrPto association is required for the activation of resistance (Scofield et al. 1996; Tang et al. 1996). The resistance also required the leucine-rich repeat protein Prf (Salmeron et al. 1996), F-box protein SGT1 (Peart et al. 2002), and HSP90 (Lu et al. 2003). The AvrPto protein targets plasma membrane through myristoylation that presumably occurs inside the plant cell. The plasma membrane localization is essential for the avirulence function in both tobacco and tomato plants (Shan et al. 2000b).

In addition to tomato plants, certain tobacco genotypes are also known to recognize avrPto and activate a HR resistance, although the corresponding resistance gene (or genes) has yet to be cloned (Shan et al. 2000b). Interestingly, the tobacco resistance gene and Pto show different recognition specificity toward mutations in the AvrPto protein (Shan et al. 2000b). A cluster of amino acids in the center of AvrPto are essential for triggering resistance mediated by Pto but are not required for recognition by tobacco. Vice versa, the carboxyl terminus is specifically required for recognition by the tobacco resistance gene but is dispensable for the interaction with Pto. However, it remains to be tested whether downstream molecular events are similar between the tobacco resistance gene and Pto. A comparative study of AvrPto function in tomato and tobacco may shed light on how disease resistance mechanisms evolve in different plant species in response to a common bacterial type III effector. To better understand molecular events in tobacco activated by AvrPto, we sought to use a "pathogen-free" system to isolate tobacco genes induced by the expression of AvrPto. In this study, we report the isolation by subtraction cloning of tobacco genes induced by the expression of the avrPto transgene under the control of a tetracycline-inducible promoter. This resulted in the isolation of 125 unique cDNA clones, including genes known to be associated with HR and a number of novel genes that have not been reported before. Most of them were induced in tobacco plants upon infection by incompatible and nonhost pathogens. Further analyses with AvrPto mutants indicated that it was the avirulence activity but not virulence activity of avrPto that induced these genes. Pto 
appeared to activate the same set of genes in tobacco plants upon the recognition of avrPto, although it was less effective than the tobacco resistance gene.

\section{RESULTS}

\section{Generation of cDNA clones \\ from suppression subtractive hybridization.}

Suppression subtractive hybridization was used to isolate cDNAs induced by AvrPto in a pathogen-independent system. Transgenic tobacco plants W38 expressing avrPto (tester) upon tetracycline infiltration and empty vector (driver) transformed plants (Shan et al. 2000b) were used in making the library. Leaf tissues were infiltrated with $1 \mathrm{mg}$ of tetracycline per milliliter for $12 \mathrm{~h}$ for RNA isolation and subtractive cDNA library construction (Diatchenko et al. 1996; Thara et al. 2004), with some modifications. A totala of 433 clones were randomly selected for sequencing, of which $90 \%$ yielded fragments greater than 200 base pairs. Comparison of these sequences revealed 125 nonoverlapping cDNA fragments. These

Table 1. cDNA clones selected for reverse Northern analysis ${ }^{\mathrm{a}}$

\begin{tabular}{|c|c|c|}
\hline Lane & Clone name & Protein homology \\
\hline 1 & Actin $^{\mathrm{a}}$ & Actin \\
\hline 2 & $A R G 1$ & (P35513) phenylalanine ammonia-lyase; tobacco \\
\hline 3 & ARG16 & $\begin{array}{l}\text { (T03275) probable cytochrome } \mathrm{P} 450, \\
\text { hypersensitivity-related; tobacco }\end{array}$ \\
\hline 4 & ARG18 & $\begin{array}{l}\text { (NP_190664) putative disease resistance protein; } \\
\text { Arabidopsis }\end{array}$ \\
\hline 5 & $A R G 2$ & $\begin{array}{l}\text { (Q03662) probable glutathione S-transferase; } \\
\text { tobacco }\end{array}$ \\
\hline 6 & ARG124 & None \\
\hline 7 & ARG3 & (CAB61885.1) glutathione-S-transferase; tomato \\
\hline 8 & ARG6 & (AAG45487) phospholipase PLD $\beta 1$; tomato \\
\hline 9 & $A R G 8$ & $\begin{array}{l}\text { (AAK54610) hypersensitive-induced response; } \\
\text { rice }\end{array}$ \\
\hline 10 & ARG11 & (P27082) superoxide dismutase [Cu-Zn]; tobacco \\
\hline 11 & ARG110 & None \\
\hline 12 & ARG7 & (AAF62403.1) harpin inducing protein; tobacco \\
\hline 13 & ARG102 & None \\
\hline 14 & $A R G 84$ & $\begin{array}{l}\text { (AAH06040) unknown (protein for MGC:7642); } \\
\text { Mus musculus }\end{array}$ \\
\hline 15 & $A R G 12$ & $\begin{array}{l}\text { (T07079) leucine-rich repeat protein LRP; } \\
\text { tomato }\end{array}$ \\
\hline 16 & ARG87 & None \\
\hline 17 & ARG89 & None \\
\hline 18 & Actin & Actin \\
\hline 19 & ARG85 & None \\
\hline 20 & ARG53 & (AAF70507.1) elongation factor- EIF4E; tomato \\
\hline 21 & $A R G 9$ & (S42807) HSR203J protein; tobacco \\
\hline 22 & $A R G 28$ & $\begin{array}{l}\text { (NP_199626) SCARECROW gene regulator; } \\
\text { Arabidopsis }\end{array}$ \\
\hline 23 & ARG106 & None \\
\hline 24 & ARG100 & None \\
\hline 25 & ARG19 & (BAA82107) NtWRKY1 (Nicotiana tabacum) \\
\hline 26 & $A R G 71$ & (CAB56815) ribosomal protein S28 \\
\hline 27 & ARG49 & $\begin{array}{l}\text { (BAB10123) berberine bridge enzyme; } \\
\text { Arabidopsis }\end{array}$ \\
\hline 28 & ARG115 & None \\
\hline 29 & $A R G 27$ & $\begin{array}{l}\text { (NP_568568) calcium-binding protein; } \\
\text { Arabidopsis }\end{array}$ \\
\hline 30 & ARG17 & (AAM19207) cysteine protease Rcr3; tomato \\
\hline 31 & $A R G 114$ & None \\
\hline 32 & ARG36 & $\begin{array}{l}\text { (NP_192994) polyubiquitin-like protein; } \\
\text { Arabidopsis }\end{array}$ \\
\hline 33 & ARG55 & $\begin{array}{l}\text { (BAB08773) translation initiation factor; } \\
\text { Arabidopsis }\end{array}$ \\
\hline 34 & $A R G 77$ & $\begin{array}{l}\text { (NP_173713) heavy-metal-associated domain- } \\
\text { containing protein; Arabidopsis }\end{array}$ \\
\hline 35 & ARG51 & (AAK14423) putative exostoses; rice \\
\hline
\end{tabular}

${ }^{a}$ The tobacco actin gene fragment (lanes 1 and 18) was used as a constitutive control. genes were named $A R G$ for avrPto-response genes. To verify the induction of $A R G$ in tobacco plants in response to the expression of the avrPto transgene, 10 clones were randomly selected for Northern analysis. Seven $A R G$ were strongly induced in plants expressing avrPto but not in control plants carrying an empty vector, indicating that the majority of the genes from the library are, indeed, differentially expressed (data not shown).

\section{Sequence comparison.}

The 125 cDNA sequences were compared with nonredundant protein databases by BlastX. A total of 86 clones show significant homology with existing sequences, while the remaining 42 do not. The cDNA clones are broadly grouped into different functional categories, according to the blast results. Among them, 19 belong to the defense category. Notable among this category are genes encoding cysteine protease (CP), HR-induced protein (HRI), phospholipase D- $\beta 1$ (PLD), phenylalanine ammonia-lyase (PAL), HSR203J, harpininduced protein (Hin1), leucine-rich repeat protein (LRP), NtWRKY1 (WRKY1), and PR proteins PR1, PR1B, PR4A, and chitinase. These genes are either known to play a role in disease resistance in other plant-pathogen systems or known to be induced during infection. Another large group is proteins involved in protein synthesis, including 20 different ribosomal protein genes. This suggests that protein synthesis is highly active in response to the avrPto expression.

Earlier work, including ours, has identified several hundred tomato genes that are either induced by the overexpression of Pto or Pto-avrPto interaction (Mysore et al. 2002, 2003; Xiao et al. 2001). To assess whether the cDNA clones isolated in this report represent novel genes or genes orthologous to the tomato genes, we compared the 125 tobacco cDNA sequences with The Institute for Genomic Research (TIGR) gene indices corresponding to the tomato cDNA clones in the three reports by Blastn. In general, tobacco and tomato orthologs share greater than $80 \%$ nucleotide sequence identity. However, only 26 tobacco cDNA clones showed similarity with the reported tomato genes at an $E$ value of $\mathrm{e}^{-4}$ or lower, suggesting that the vast majority of the tobacco clones represent new genes that have not been isolated by the previous work with tomato.

Gene expression in incompatible and nonhost interactions.

We selected $33 A R G$, including genes related to defense/stress response, signal transduction, metabolism, hypothetical, and novel genes (Table 1) and examined their expression during infection by compatible and incompatible interactions. W38 plants were inoculated with $P$. syringae pv. tabaci with (RA) or without (R) the avrPto gene for $12 \mathrm{~h}$, and gene expression was examined by reverse Northern (Fig. 1). Most $A R G$ were expressed more strongly when induced by RA as compared with $\mathrm{R}$. The exceptions were lanes 2, 3, 10, 15, and 32 shown in Figure 1, containing PAL (ARGl), cytochrome P450 (ARGl6), superoxide dismutase (SOD; ARG11), LRP (ARG12), and polyubiquitin protein $(A R G 36)$ genes that were also induced by the compatible $\mathrm{R}$ strain. Of the $33 A R G$ tested by reverse Northern, 27 showed an induced expression in the incompatible interaction, indicating that the majority of $A R G$ examined were induced when AvrPto was delivered by the bacterium.

Northern analysis was performed to further examine the induction of six $A R G$ that were induced during the incompatible interaction. These are PLD, HRI, SOD, WRKY1, CP, and a novel gene (NV) (Table 1, row 24). HRI, PLD, and CP were induced specifically in W38 plants inoculated with RA but not those with R (Fig. 2). SOD, WRKY1, and NV were induced in W38 by both R and RA, but RA showed much greater induction of these genes between 9 and $24 \mathrm{~h}$ after inoculation. 
To determine whether the $A R G$ were induced in response to any other HR-inducing pathogen, we examined the $33 A R G$ described above for their expression in response to nonhost bacteria $P$. syringae pv. tomato DC3000 (a tomato pathogen) and $P$. syringae pv. phaseolicola (a bean pathogen) and Tobacco mosaic virus (TMV). DC3000 contains the avrPto gene, whereas the $P$. syringae pv. phaseolicola strain does not. The bacteria were inoculated onto W38 plants, and TMV was inoculated onto two Nicotiana sylvestris lines containing the NN gene (incompatible) and the $n n$ gene (compatible), according to Yang et al., (1996). Similar to the incompatible RA strain, the nonhost bacteria induced expression of the majority of $A R G$ to high levels (Fig. 1). The NN-TMV interaction also induced many of the genes tested although at a lower level. Northern analysis confirmed the induction of six $A R G$ in response to DC3000 infiltration and NN-TMV interaction (Fig. 2 ). It may be noted that the accumulation of all transcripts except $\mathrm{CP}$ begins at $6 \mathrm{~h}$ postinoculation in DC3000 (Fig. 2) compared with 9 to $12 \mathrm{~h}$ in $P$. syringae pv. tabaci RA inoculation. The treatment with buffer or virulent pathogen had little or no effect on $A R G$ transcript levels (except for SOD). All six $A R G$ tested were induced in NN plants compared with nn plants 72 $\mathrm{h}$ after TMV inoculation, although less than the induction by DC3000 infection. Northern blots detected two different transcript sizes for WRKY1, PLD, CP, and NV (Fig. 2). The transcripts could be due to the presence of different gene family members or to alternative splicing.

\section{AvrPto mutants fail to induce gene expression.}

Because AvrPto is known to act both as a virulence and an avirulence factor, we sought to determine if the observed gene induction was caused by gene-for-gene interaction or virulence. Previously, we showed that the C-terminus of AvrPto is required for the gene-for-gene recognition in tobacco plants, whereas the N-terminal myristoylation motif is essential for gene-for-gene recognition in both tobacco and tomato plants (Shan et al. 2000b). Previous work also showed that an amino acid sequence motif at the center of AvrPto is required for gene-for-gene recognition in tomato plants but is not required for virulence (Shan et al. 2000a). We tested whether the C-terminal motif was required for virulence function by using the previously characterized mutant P146L. This single amino acid substitution in AvrPto abolishes HR resistance in tobacco plants (Shan et al. 2000b). Figure 3A shows that $P$. syringae pv. tomato carrying the wild-type avrPto or the P146L mutant compared with the strain without an avrPto gene grew to higher populations in the susceptible tomato cultivar PtoS. We repeatedly saw a small $(0.4$ to $0.6 \mathrm{log})$ but consistent increase in bacterial growth that is typical for the AvrPto virulence activity. Similarly, $P$. syringae pv. tabaci carrying P146L grew to a higher population in tobacco W38 plants when compared with the strain lacking the avrPto gene (Fig. 3B). Thus the P146L mutant had normal virulence function in both $P$. syringae pv. tabaci and $P$. syringae pv. tomato. In contrast, the $P$. syringae pv. tomato strain carrying the avrPto G2A mutant, which contains a single amino acid substitution abolishing

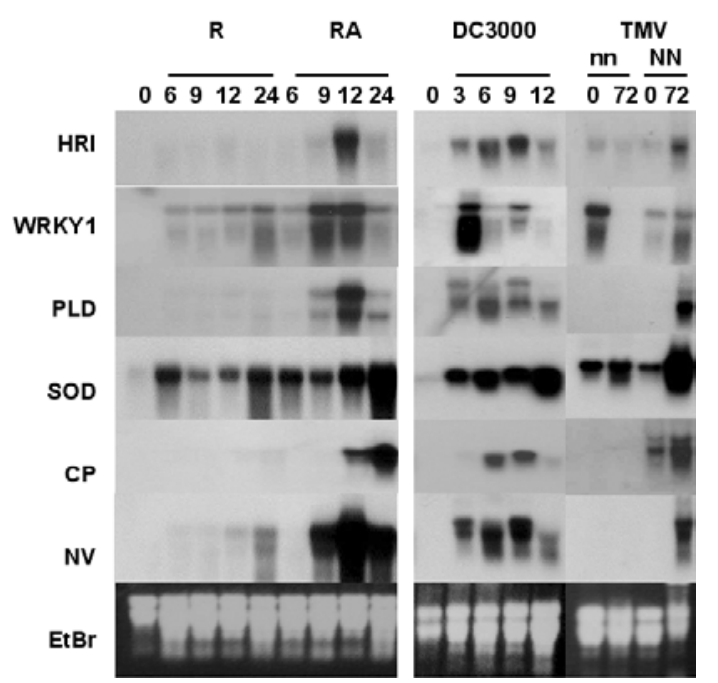

Fig. 2. Northern analysis of gene expression during incompatible interactions. W38 plants were inoculated with Pseudomonas syringae pv. tabaci R (W38/R), P. syringae pv. tabaci R carrying avrPto (W38/RA), P. syringae pv. tomato DC3000 (W38/DC3000), and $P$. syringae phaseolicola (W38/P.s.ph), and Nicotiana sylvestris susceptible (nn) and resistant (NN) plants were inoculated with Tobacco mosaic virus (TMV) at indicated hours, and RNA was isolated for Northern analyses. cDNA probes corresponding to a hypersensitive response-induced gene (HR), NtWRKY1 (WRKY1), phospholipase D (PLD), superoxide dismutase (SOD), cysteine proteinase (CP), and a novel gene (NV) were labeled with $\mathrm{P}^{32} \mathrm{dCTP}$ for probing. Total RNA $(10 \mu \mathrm{g})$ was used in each lane, and equal loading of RNA is shown by ethidium bromide staining ( $\mathrm{EtBr})$. The Northern has been repeated twice with similar results.

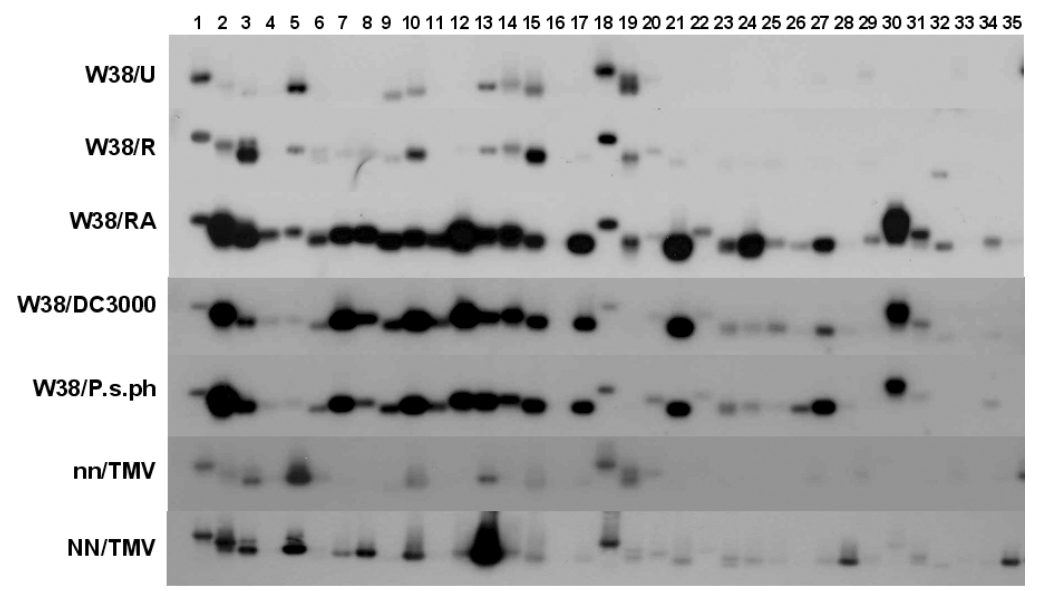

Fig. 1. Reverse Northern analysis of gene expression during incompatible interactions. Filters containing 33 selected cDNA clones were probed with $\mathrm{P}^{32}$ labeled total cDNA from W38 leaves $12 \mathrm{~h}$ after inoculation with Pseudomonas syringae pv. tabaci (R), P. syringae pv. tabaci carrying avrPto (RA), $P$. syringae pv. tomato DC3000 (DC3000), and P. syringae pv. phaseolicola (P.s.ph), and Nicotiana sylvestris susceptible (nn) and resistant (NN) plants $72 \mathrm{~h}$ after inoculation with Tobacco mosaic virus (TMV). Lanes 1 and 18 are loaded with the constitutive control actin. The experiment was repeated twice with similar results. 
myristoylation in the plant, grew to the same level when compared with the strain without an avrPto gene, indicating that the myristoylation motif was required for virulence function (Fig. 3A).

We next used these mutants to characterize tobacco $A R G$. Transgenic plants expressing the avrPto P146L and G2A mutants were examined by reverse Northern for the expression of the 33 selected genes. As shown in Figure 4, while the tetracycline induction of the wild-type avrPto transgene expression in tobacco strongly induced the majority of the $33 A R G$, the

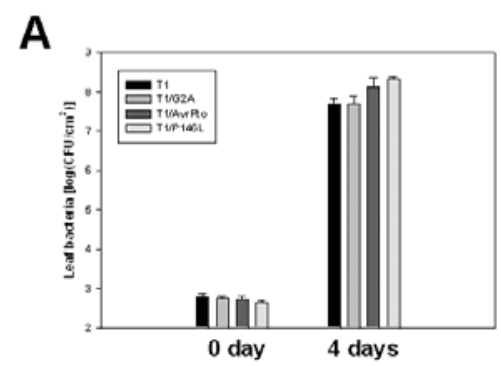

B

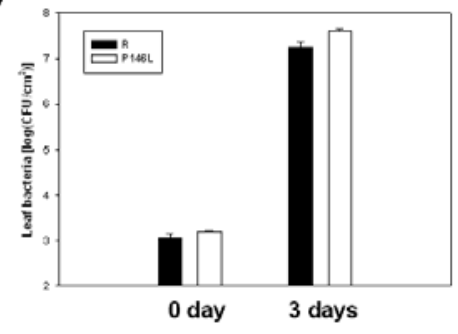

Fig. 3. Effects of the G2A and P146L mutations on AvrPto virulence activity. A, Virulence activities of the G2A and P146L mutants in tomato plants. Tomato PtoS plants were vacuum-infiltrated with the Pseudomonas syringae strains T1 or T1 carrying the wild-type avrPto or G2A and P146L mutants at $10^{5} \mathrm{CFU} / \mathrm{ml}$, and leaf bacterial populations were measured at 0 and 4 days after inoculation. Each data point represents an average of four replicates. Error bars represent standard errors. The bacterial numbers of tomato leaves inoculated with $\mathrm{T} 1$ or T1 carrying the G2A mutant were significantly lower $(P=0.05)$ than leaves inoculated with T1 carrying either the wild-type avrPto or the P146L mutant four days after inoculation, as determined by Student's $t$ test. B, Virulence activity of the P146L mutant in tobacco plants. W38 plants were syringe-inoculated with $P$. syringae $\mathrm{pv}$. tabaci strain R or R carrying $\mathrm{P} 146 \mathrm{~L}$ at $10^{5} \mathrm{CFU} / \mathrm{ml}$, and leaf bacterial populations were measured at 0 and 3 days after inoculation. Each data point represents an average of four replicates. Error bars represent standard errors. The bacterial numbers of $\mathrm{R}$ and P146L-inoculated tobacco leaves at 3 days were statistically significant $(P=0.05)$, as determined by Student's $t$ test. The bacterial growth assays were repeated three times with similar results.
P146L and G2A mutants failed to induce the selected tobacco genes. The only exception was the reduced expression of a cytochrome P450 gene (Fig 4, lane 3) in plants expressing the two mutants. The presence of the AvrPto protein in these plants was verified by Western blot (data not shown), indicating that the lack of gene induction was not caused by the lack of protein accumulation. The results indicate that the induced $A R G$ expression by avrPto was not a result of virulence function. Instead, gene-for-gene recognition was responsible for the observed gene induction.

Northern analysis of five incompatible-specific $A R G$ showed that their transcripts were induced to higher levels at 9 to12 $\mathrm{h}$ postinoculation in transgenic plants expressing the wild-type avrPto compared with plants transformed with an empty vector (EV) or the P146L and G2A mutants (Fig. 5). The lack of $A R G$ induction in plants expressing the avrPto mutants demonstrates that the avirulence activity of AvrPto is essential for the induction of $A R G$.

\section{Induced gene expression upon Pto-avrPto recognition.}

The tomato Pto and tobacco resistance genes both recognize the avrPto gene and activate HR resistance. Previous studies indicated that the recognition by Pto and the tobacco resistance gene required different motifs within the AvrPto protein. P146L can only be recognized by the $35 \mathrm{~S}:$ :Pto transgene in tobacco plants but not the native tobacco resistance gene (Shan et al. $2000 \mathrm{~b}$ ). We tested whether the tobacco genes induced by the tobacco resistance gene were also induced by Pto. W38 plants carrying the 35S::Pto transgene (Thilmony et al. 1995) and nontransgenic W38 plants were inoculated with $P$. syringae pv. tabaci carrying $\mathrm{P} 146 \mathrm{~L}$ or the wild-type avrPto. Northern analysis was used to examine the expression of five genes, NV, CP, PLD, WRKY1, and HRI. As expected, inoculation of W38 plants with the strain carrying P146L failed to induce any gene $12 \mathrm{~h}$ after inoculation. In contrast, inoculation of the 35S::Pto transgenic or W38 plants with strains carrying the wild-type avrPto strongly induced all five genes. Inoculation of 35S::Pto plants with the strain containing P146L induced four of the five genes tested at the 12-h timepoint (Fig. 6). The induction of NV and HRI genes was weaker in 35S::Pto tobacco plants inoculated with the P146L strain than in plants inoculated with the wild-type avrPto strain. CP was not induced in 35S::Pto plants inoculated with the P146L strain at the 12-h timepoint but was induced weakly at a later timepoint in other experiments (data not shown). Overall, these results indicate that Pto and the tobacco resistance gene induce similar sets of genes upon recognition of avrPto, although Pto does so less effectively.

In tomato plants, overexpression of Pto constitutively activates defense gene expression and causes microscopic lesions.

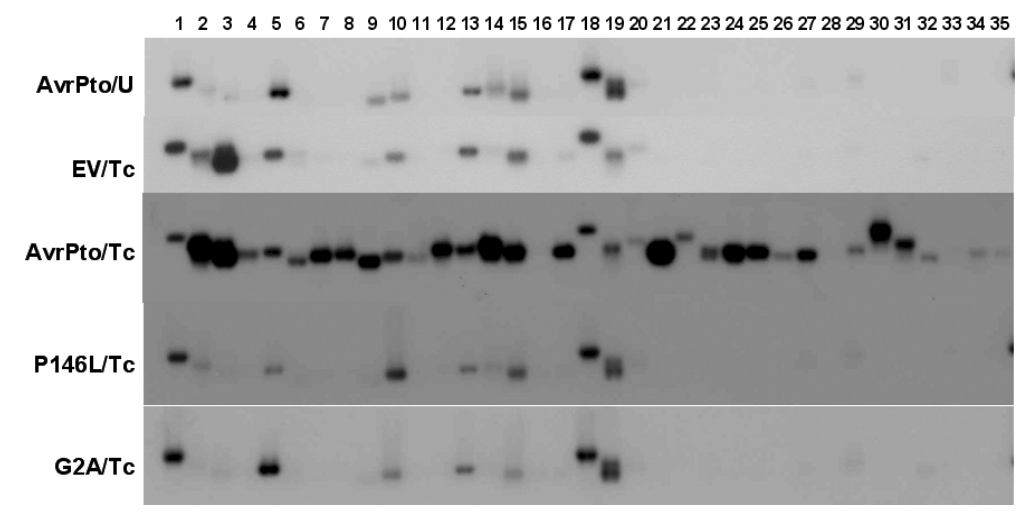

Fig. 4. Reverse Northern analysis of tobacco plants expressing the G2A and P146L mutants. Transgenic plants carrying either the empty vector (EV), wildtype avrPto transgene (line 16), or the G2A or P146L mutant transgene were untreated (U) or infiltrated with tetracycline (Tc) at $1 \mathrm{mg} / \mathrm{ml}$, and RNA was isolated $12 \mathrm{~h}$ after infiltration for reverse Northern analyses. The results are representative of two independent experiments. 
However, our previous work suggested that the pathway activated by Pto overexpression is different from that activated by Pto-avrPto interaction. To further test this possibility, we examined the expression of five ARG, HRI, HSR203J, Hinl, $P L D$, and $W R K Y 1$, in a Pto-overexpressing tomato line (Fig. 7). None of the five $A R G$ tested showed increased expression in Pto-overexpression plants compared with nontransgenic tomato plants.

\section{DISCUSSION}

The use of an inducible promoter to drive the expression of the bacterial effector gene avrPto led to the isolation of 125 unique cDNA clones. Reverse Northern and Northern analyses show that most of these genes are induced by the tobacco resistance gene and Pto upon specific recognition of avrPto. These genes are also induced in tobacco plants inoculated with HR-inducing nonhost Pseudomonas strains and during the $N$ gene-mediated resistance. Therefore, the expression of many of the $A R G$ is associated with HR.

AvrPto is a virulence factor and contributes to increased bacterial growth on susceptible plants lacking a corresponding disease resistance gene. In order to differentiate plant genes induced by gene-for-gene resistance from those induced by the virulence function of AvrPto, we characterized tobacco gene expression in response to the AvrPto G2A and P146L mutants. The G2A mutation disrupts the myristoylation-mediated plasma membrane association and gene-for-gene resistance in tobacco and tomato plants (Shan et al. 2000b), but its effect on virulence function has not been tested. We show here that this mutation also abolished the virulence function. In contrast, the P146L mutation disrupts recognition by the tobacco resistance gene but had no effect on the virulence function in tomato and tobacco plants. When expressed in tobacco plants, neither mutant induced the 33 genes examined, indicating that the virulence activity of AvrPto did not result in the induced expression of the tobacco genes. Instead, the avirulence function was essential for gene induction. The results also suggest that the virulence function of AvrPto has little effect on gene induction in tobacco. In Arabidopsis, overexpression of AvrPto represses the expression of genes associated with cell wall defense (Hauck et al. 2003). Perhaps the AvrPto effector exerts the virulence function primarily by repression instead of induction of host genes.

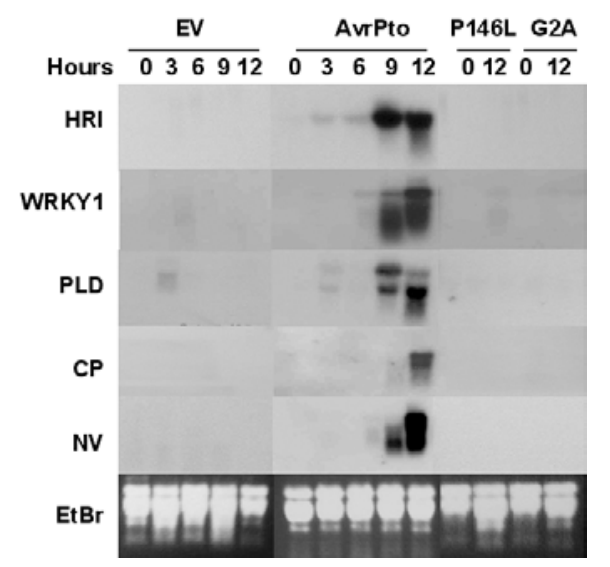

Fig. 5. Northern analysis of tobacco plants expressing the G2A and P146L mutants. Transgenic plants carrying either empty vector (EV), wild-type avrPto transgene (line 16), the G2A mutant transgene, or the P146L mutant transgene were infiltrated with tetracycline at $1 \mathrm{mg} / \mathrm{ml}$, and RNA was isolated at the indicated timepoints for Northern analyses. Ethidium bromide staining $(\mathrm{EtBr})$ indicates equal loading of RNAin all lanes. The Northern analysis has been repeated twice with similar results.
The predicted protein sequences of the cDNA clones suggest that many of the $A R G$ are functionally relevant to defense responses associated with gene-for-gene resistance. For example, the cysteine protease (ARG17) isolated in this study is a likely ortholog of the tomato Rcr3 protein that is required for $C f$-2-dependant disease resistance to the fungal pathogen Cladosporium fulvum (Kruger et al. 2002). Two cDNA clones encode leucine-rich repeat (LRR) proteins (ARG12 and $A R G 18$ ). Activation of LRR resistance genes has been found to amplify gene-for-gene disease resistance (Xiao et al. 2003). NtWRKY1 (ARG19) is known to be induced by an elicitor (accession number BAA82107). WRKY transcription factors play an important role in plant defense (Eulgem et al. 2000). A tomato homolog of NtWRKY1 was shown to be induced by Pto-avrPto recognition (Mysore et al. 2002). Two cDNA clones (ARG38 and ARG39) encode thioreduxins that are involved in redox regulation of proteins. Recent findings indicate that redox regulation plays a major role in regulating de-

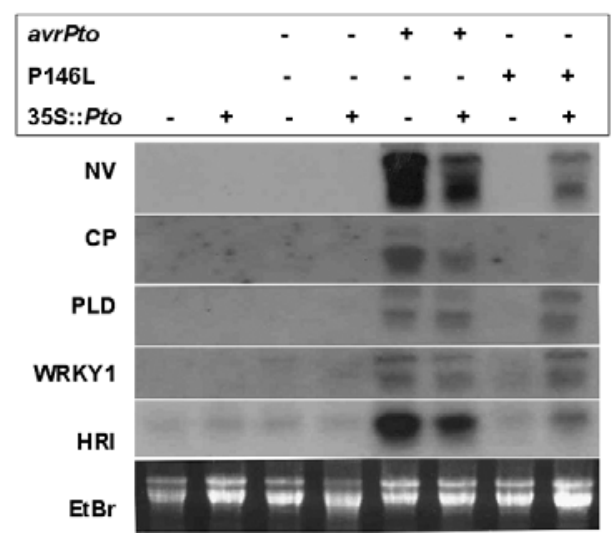

Fig. 6. Northern analysis of gene expression during Pto-P146L interaction in tobacco plants. W38 plants with $(+)$ or without $(-)$ the $35 \mathrm{~S}::$ Pto transgene were inoculated with Pseudomonas syringae pv. tabaci $\mathrm{R}$ strains lacking avrPto (lanes 3 and 4) or carrying either the wild-type avrPto (lanes 5 and 6) or P146L (lanes 7 and 8) or for $12 \mathrm{~h}$ of RNA isolation. Lanes 1 and 2 are uninoculated RNA samples. Northern blots were hybridized with the indicated cDNA probes. Ethidium bromide staining indicates equal loading of RNA in all lanes. The experiment was repeated three times with similar results.

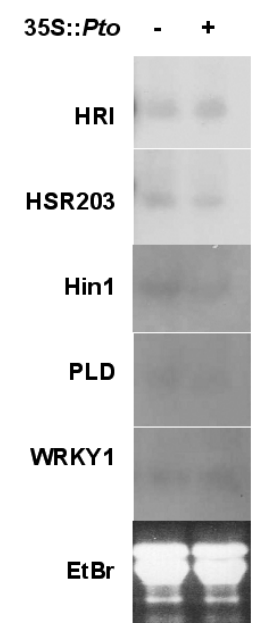

Fig. 7. Northern analysis of avrPto-response genes in tomato plants overexpressing Pto. RNA was extracted from uninoculated transgenic tomato line 135 carrying the $35 \mathrm{~S}:$ : Pto transgene (+) or nontransgenic PtoS plants (-). The 35S::Pto plants exhibited typical microscopic lesions. RNA blots were hybridized with the indicated tobacco cDNA probes. Ethidium bromide staining indicates equal loading of RNA in all lanes. The results shown are representative of two independent experiments. 
fense gene expression in plants. For example, NPR1 exists as an oligomer in the cytoplasm in the absence of a systemic acquired resistance (SAR) signal. In the presence of a SAR signal, NPR1 is reduced by reduced redox state, allowing nuclear translocation and activation of downstream defense genes (Mou et al. 2003). Similarly, redox regulation of the transcription factor TGA1 is required for its interaction with NPR1 and subsequent PR gene transcription (Despres et al. 2003). $A R G 33$ and $A R G 36$ encode an F-box protein and a polyubiquitin protein, respectively. The ubiquitin pathway plays an important role in gene-for-gene resistance (Devoto et al. 2003). Another gene worth mentioning is PLD- $\beta 1$. PLDs have been implicated in several cellular and signaling events (Wang et al. 2002). Laxalt and associates (2001) have shown the rapid induction of PLD- $\beta 1$ in tomato upon treatment with the fungal elicitor xylanase and not chitotetrose. Their role in HR or gene-for-gene resistance is not known.

Overexpression of Pto in tomato constitutively activates defense responses and cell death. Several mutations in Pto abolish all these constitutive defense responses but do not affect HR and resistance when the plant is infected with $P$. syringae pv. tomato (avrPto) (Xiao et al. 2003). Therefore, we have suggested that gene-for-gene resistance and overexpression of Pto-induced resistance are through distinct mechanisms. Consistent with this hypothesis, none of the five $A R G$ tested in this study showed increased expression in tomato plants overexpressing Pto.

Previous studies in tomato plants collectively identified approximately 600 genes that are either induced by overexpression of Pto or by Pto-avrPto recognition (Xiao et al. 2001; Mysore et al. 2002, 2003). Most of the tobacco cDNA clones reported here represent genes that have not been identified in the previous tomato work. Only 26 of the 125 tobacco cDNA clones were homologous to the tomato genes in those three reports. This work has significantly expanded the catalog of the existing genes known to be activated by Pto-avrPto interaction. The availability of a large collection of response genes will facilitate the molecular characterization of defense pathways mediated by Pto and the tobacco resistance gene in both tomato and tobacco plants.

\section{MATERIALS AND METHODS}

\section{Plant materials.}

The tobacco plants used in this study were as follows: nontransgenic W38, W38 35S::Pto (Thilmony et al. 1995), W38 TetR/pBin-hyg-TX (EV), W38 TetR/avrPto line 16, W38 TetR/P146L (P146L), W38 TetR/G2A (G2A) (Shan et al. 2000b). Tomato lines used included nontransgenic Rio Grande PtoS and PtoS transgenic line 135 carrying 35S::Pto (Xiao et al. 2003). PtoR carries an endogenous Pto, whereas PtoS does not. All plants were grown in the greenhouse. Ten-week-old tobacco plants and five-week-old tomato plants were used in experiments.

\section{Construction of subtracted cDNA library.}

Leaf tissue from 10 plants of line 16 and EV at one week old were infiltrated with $1 \mathrm{mg}$ of tetracycline per liter. Leaf tissues ( 7 to $8 \mathrm{~g}$ ) were collected $12 \mathrm{~h}$ postinfiltration and were frozen in liquid nitrogen. Total RNA was extracted as according to Thara and associates (1999). A Poly(A)tract mRNA isolation kit from Promega (Madison, WI, U.S.A.) was used to isolate mRNA from 1 to $2 \mu \mathrm{g}$ of total RNA, according to manufacturer's instructions. Two micrograms of mRNA was used in constructing the subtracted library. cDNA from EV plants and line 16 infiltrated with tetracycline were used as driver and tester, respectively. Suppression subtractive hybridi- zation (Diatchenko et al. 1996) was carried out using the PCR Select-Subtraction cDNA kit (Clontech, Palo Alto, CA, U.S.A.), with some modifications. The modifications were: Adaptor 1 and 2 ligated products were diluted five times, and 1 $\mu \mathrm{l}$ of each was incubated with $2 \mu \mathrm{l} R s \mathrm{I}$-digested driver during the first hybridization. The subtracted cDNA was digested with $R s a \mathrm{I}$, was blunt-ended by Klenow fill-in, was fractioned through agarose gel for cDNA greater than $300 \mathrm{bp}$, and was ligated into pBluescript digested with SmaI before being transformed into Escherichia coli XL1-Blue. Individual colonies were picked randomly and sequenced.

\section{Sequence analyses.}

The cDNA sequences were processed as follows. Cross_match and Repeat Masker were used to remove vector sequences and linkers from the tobacco sequences. The resulting sequences were assembled using phrap for assembly, and redundant cDNA sequences were removed using a Perl program. To compare with the tomato cDNA sequences of Xiao and associates (2001) and Mysore and associates (2002, 2003), unigene sequences corresponding to the reported expressed sequence tags were retrieved from the TIGR gene indices database. The tobacco cDNA sequences were then used as query sequences for BLASTN analysis. Tobacco sequences sharing little homology $\left(E>\mathrm{e}^{-5}\right)$ with the tomato sequences were considered "novel."

\section{Pathogen inoculation and bacterial growth assay.}

Bacterial strains $P$. syringae pv. tabaci 1152 with (RA) or without (R) avrPto or with the G2A or P146L mutant of avrPto and $P$. syringae pv. tomato DC3000 were inoculated onto tobacco plants. For tomato inoculation, $P$. syringae pv. tomato strains with (T1A) or without (T1) avrPto were used. A concentration of $2 \times 10^{6} \mathrm{CFU} / \mathrm{ml}$ was used for all Northern and reverse Northern experiments. For bacterial growth assay, $10^{5} \mathrm{CFU}$ of bacteria per milliliter were syringe-infiltrated into tobacco plants and vacuum-infiltrated into tomato plants, and leaf bacterial populations were determined as described by Shan and associates (2000b).

Viral inoculations on $N$. sylvestris $N N$ and $n n$ plants were carried out according to Yang and associates (1996).

\section{Protein extraction and Western analysis.}

To determine the expression of P146L or G2A in the respective transgenic plants, we performed Western analysis. Leaves of transgenic plants were inoculated with $1 \mathrm{mg}$ of tetracycline per milliliter, and tissues were harvested $12 \mathrm{~h}$ postinfiltration. Protein extractions and Western blotting was done according to Shan and associates (2000b).

\section{Northern analysis.}

Total RNA $(10 \mu \mathrm{g})$ was electrophoresed in formaldehydeagarose denaturing gel and was transferred to Hybond $\mathrm{N}+$ membranes (Amersham, Buckinghamshire, England) using $10 \times \mathrm{SSC}(1 \times \mathrm{SSC}$ is $0.15 \mathrm{M} \mathrm{NaCl}$ plus $0.015 \mathrm{M}$ sodium citrate). RNA was immobilized to the membrane by UV crosslinking. Membranes were prehybridized using modified buffer as described by Thara and associates (1999). All prehybridizations and hybridizations were carried out at $65^{\circ} \mathrm{C}$. All probes were generated by polymerase chain reaction (PCR), using standard $\mathrm{T} 3$ and $\mathrm{T} 7$ primers.

\section{Reverse Northern analysis.}

PCR products of cDNA clones were electrophoresed in $0.8 \%$ agarose gels and were transferred to HybondN+ using $0.4 \mathrm{~N}$ sodium hydroxide. Tobacco actin (accession number U60495) was amplified by PCR from genomic DNA, using 
the primers 5'-TGCTGGTGATGATGCTCCTAGAG-3' and 5' TGCGAGGATGGATCCTCCGATC-3'. Duplicate blots were probed separately with radio-labeled cDNA probes reversetranscribed from $40 \mu \mathrm{g}$ of total RNA (Thara et al. 2004).

\section{ACKNOWLEDGMENTS}

The authors are grateful to J. Shah, F. White, and B. Valent for critically reading the manuscript, $\mathrm{B}$. Porter for setting up batch blasts and help with photography, and D. Baker for excellent technical assistance. This project was funded in part by a grant from National Science Foundation (MCB9808701) to J.-M. Zhou and a United States Department of Agriculture grant (9802511) to X. Tang. This paper is a contribution of the Kansas Agriculture Experimental Station (04-419-J).

\section{LITERATURE CITED}

Axtell, M. J., and Staskawicz, B. J. 2003. Initiation of RPS2-specified disease resistance in Arabidopsis is coupled to the AvrRpt2-directed elimination of RIN4. Cell. 112:369-377.

Chang, J. H., Goel, A. K., Grant, S. R., and Dangl, J. L. 2004. Wake of the flood: Ascribing functions to the wave of type III effector proteins of phytopathogenic bacteria. Curr. Opin. Microbiol. 7:11-18.

Despres, C., Chubak, C., Rochon, A., Clark, R., Bethune, T., Desveaux, D. and Fobert, P. R. 2003. The Arabidopsis NPR1 disease resistance protein is a novel cofactor that confers redox regulation of DNA binding activity to the basic domain/leucine zipper transcription factor TGA1. Plant Cell 15:2181-2191.

Devoto, A., Muskett, P. R.. and Shirasu, K. 2003. Role of ubiquitination in the regulation of plant defence against pathogens. Curr. Opin. Plant Biol. 6:307-311.

Diatchenko, L., Lau, Y. C., Campbell, A., Chenchik, A., Moqadam, F., Huang, B., Lukyanov, S. A., Lukyanov, K., Gurskaya, N., Sverdlov, E. D., and Siebert, P. D. 1996. Suppression substractive hybridization: A method for generating differentially regulated or tissue-specific cDNA probes and libraries. Proc. Natl. Acad. Sci. U.S.A. 93:6025-6030.

Eulgem, T., Rushton, P. J., Robatzek, S., and Somssich, I. E. 2000. The WRKY superfamily of plant transcription factors. Trends Plant Sci. 5:199-206.

Flor, H. H. 1956. The complementary genic systems in flax and flax rust. Adv. in Genet. 8:29-54.

Galan, J. E., and Collmer, A. 1999. Type III secretion machines: Bacterial devices for protein delivery into host cells. Science. 284:1322-1328.

Hauck, P., Thilmony, R., and He, S.Y. 2003. A Pseudomonas syringae type III effector suppresses cell wall-based extracellular defense in susceptible Arabidopsis plants. Proc. Natl. Acad. Sci. U.S.A. 100:85778582.

Kruger, J., Thomas, C. M., Golstein, C., Dixon, M. S., Smoker, M., Tang, S., Mulder, L., and Jones, J. D. 2002. A tomato cysteine protease required for Cf-2-dependent disease resistance and suppression of autonecrosis. Science. 296:744-747.

Laxalt, A. M., ter Riet, B., Verdonk, J. C., Parigi, L., Tameling, W. I., Vossen, J., Haring, M., Musgrave, A., and Munnik, T. 2001. Characterization of five tomato phospholipase D cDNAs: Rapid and specific expression of LePLDbeta1 on elicitation with xylanase. Plant J. 26:237-247.

Lu, R., Malcuit, I., Moffett, P., Ruiz, M. T., Peart, J., Wu, A. J., Rathjen, J. P., Bendahmane, A., Day, L., and Baulcombe, D. C. 2003. High throughput virus-induced gene silencing implicates heat shock protein 90 in plant disease resistance. EMBO (Eur. Mol. Biol. Organ.) J. 22:5690-5699.

Mackey, D., Holt, B. F., Wiig, A., and Dangl, J. L. 2002. RIN4 interacts with Pseudomonas syringae type III effector molecules and is required for RPM1-mediated resistance in Arabidopsis. Cell 108:743-754.
Mou, Z., Fan, W., and Dong, X. 2003. Inducers of plant systemic acquired resistance regulate NPR1 function through redox changes. Cell 113:935-944.

Mysore, K. S., Crasta, O. R., Tuori, R. P., Folkerts, O., Swirsky, P. B., and Martin, G. B. 2002. Comprehensive transcript profiling of Pto- and Prfmediated host defense responses to infection by Pseudomonas syringae pv. tomato. Plant J. 32:299-315.

Mysore, K. S., D'Ascenzo, M. D., He, X., and Martin, G. B. 2003. Overexpression of the disease resistance gene Pto in tomato induces gene expression changes similar to immune responses in human and fruit fly. Plant Physiol. 132:1901-1912.

Nimchuk, Z., Marois, E., Kjemtrup, S., Leister, R. T., Katagiri, F., and Dangl, J. L. 2000. Eukaryotic fatty acylation drives plasma membrane targeting and enhances function of several type III effector proteins from Pseudomonas syringae. Cell 101:353-363.

Peart, J. R., Lu, R., Sadanandom, A., Malcuit, I., Moffett, P., Brice, D. C., Schauser, L., Jaggard, D. A., Xiao, S., Coleman, M. J., Dow, M., Jones, J. D., Shirasu, K., and Baulcombe, D. C. 2002. Ubiquitin ligase-associated protein SGT1 is required for host and nonhost disease resistance in plants. Proc. Natl. Acad. Sci. U.S.A. 99:10865-10869.

Salmeron, J. M., Oldroyd, G. E., Rommens, C. M., Scofield, S. R., Kim, H. S., Lavelle, D. T., Dahlbeck, D., and Staskawicz, B. J. 1996. Tomato Prf is a member of the leucine-rich repeat class of plant disease resistance genes and lies embedded within the Pto kinase gene cluster. Cell. 86:123-133.

Scofield, S. R., Tobias, C. M., Rathjen, J. P., Chang, J. H., Lavelle, D. T., Michelmore, R. W., and Staskawicz, B. J. 1996. Molecular basis of gene-for-gene specificity in bacterial speck disease of tomato. Science 274:2063-2065.

Shan, L., He, P., Zhou, J. M., and Tang, X. 2000a. A cluster of mutations disrupt the avirulence but not the virulence function of AvrPto. Mol. Plant Microbe Interact. 13:592-598.

Shan, L., Thara, V. K., Martin, G. B., Zhou, J. M., and Tang, X. 2000 b. The Pseudomonas AvrPto protein is differentially recognized by tomato and tobacco and is localized to the plant plasma membrane. Plant Cell 12:2323-2338.

Tang, X., Frederick, R. D., Zhou, J., Halterman, D. A., Jia, Y., and Martin, G. B. 1996. Initiation of plant disease resistance by physical interaction of AvrPto and Pto kinase. Science 274:2060-2063.

Thara, V. K., Tang, X., Gu, Y. Q., Martin, G. B., and Zhou, J. M. 1999. Pseudomonas syringae pv. tomato induces the expression of tomato EREBP-like genes pti4 and pti5 independent of ethylene, salicylate and jasmonate. Plant J. 20:475-483.

Thara, V. K., Fellers, J. P., and Zhou, J. M. 2004. Isolation and characterization of in planta induced genes of Puccinia triticina. Mol. Plant Pathol. 4:51-56.

Thilmony, R. L., Chen, Z., Bressan, R. A., and Martin, G. B. 1995. Expression of the tomato Pto gene in tobacco enhances resistance to Pseudomonas syringae pv. tabaci expressing avrPto. Plant Cell 7:1529-1536.

Wang, X, Wang, C., Sang, Y., Qin, C., and Welti, R. 2002. Networking of phospholipases in plant signal transduction. Physiol. Plant. 115:331-335.

Xiao, F., Tang, X., and Zhou J. M. 2001. Expression of 35S::Pto globally activates defense-related genes in tomato plants. Plant Physiol. 1261:1637-1645

Xiao, S., Brown, S., Patrick, E., Brearley, C., and Turner, J. G. 2003. Enhanced transcription of the Arabidopsis disease resistance genes RPW8.1 and RPW8.2 via a salicylic acid-dependent amplification circuit is required for hypersensitive cell death. Plant Cell 15:33-45.

Yang, Y., and Klessig, D. F. 1996. Isolation and characterization of a tobacco mosaic virus-inducible myb oncogene homolog from tobacco. Proc. Natl. Acad. Sci. U.S.A. 93:14972-14977.

Zhao, Y., Thilmony, R., Bender, C. L., Schaller, A., He, S. Y., and Howe, G. A. 2003. Virulence systems of Pseudomonas syringae pv. tomato promote bacterial speck disease in tomato by targeting the jasmonate signaling pathway. Plant J. 36:485-499. 